\title{
THE TRAGEDY OF LOCAL SERVICE SHORTAGE IN CITIES - A WILLINGNESS TO PAY STUDY
}

\author{
M. HARALDSSON \& T. SVENSSON \\ VTI, Sweden.
}

\begin{abstract}
The transformation of the grocery retailing business witnessed in many countries during the last decades has resulted in sparser retailing networks, wherein firm efficiency has improved at the expense of store proximity. This process is welfare enhancing in most cases, but one potential source of market failure remains to be explored. There might exist a degenerative process, caused by uncoordinated individual interaction, creating unmatched demand for local service. The purpose of this paper is to test if local grocery retailing service is a utility plagued by a social dilemma. When a social dilemma is at hand, each individual realises that the impact of his/her choices is too small to make a difference, if others cannot be trusted to act in the same manner. Under this hypothesis, more local service would be observed if individual actions could be coordinated. In a stated preference study, more than 2000 respondents have stated how they would distribute their grocery purchases between a local store $300 \mathrm{~m}$ from their homes and a larger, but cheaper, store $10 \mathrm{~km}$ away. In a first scenario they do this under the condition that their choice does not affect the existence or design of any of the two stores. This mirrors the realistic case with uncoordinated decisions and negligible individual influence. In a second scenario, the respondents make the same choice but are now informed that the share they buy in the small store will affect the price level and ultimately the survival of the small store. In this way we mimic a case where individuals could trust each other and make short-term sacrifices for a long-term benefit. Based on the answers we estimate the willingness to pay (WTP) for local grocery service. It is found that WTP would be higher if the shopping behaviour could be coordinated. With some sort of binding agreement between the customers, the local store would survive and offer better service and more favourable lower prices than if people act independently. A policy recommendation is to support local grocery stores, not by direct regulations, but through a transport system and a land use pattern that makes local service more favourable.

Keywords: grocery stores, retailing, social dilemma, urban transport, willingness to pay.
\end{abstract}

\section{INTRODUCTION}

Grocery stores provide consumers not only with physical utilities, but with a package of convenience dimensions as well. Among these belong, for instance, several distributional services. To compile a set of adequate commodities and provide these to customers in appropriate volumes, at convenient places and at convenient times is an utility as important as the commodities themselves [1]. The demand for the convenience dimension store proximity explains the existence of smaller stores close to residential areas; consumers might be willing to pay for local service. However, the rapid transformation of the grocery retailing business witnessed in many countries in the last decades has resulted in a sparser retailing network, wherein firm efficiency has improved at the expense of store proximity.

Using data set from The Swedish Consumer Agency we earlier found a significant negative relationship between price and store size [2], showing that lower price has been substituted for store proximity. These scale economies explain and to some extent justify the transformation from a welfare economic point of view. Based on extensive research $[2,3]$ our view is that the change towards a sparser grocery distribution network with larger units is welfare enhancing under many circumstances. We have earlier contributed by a model study showing how a socially optimal grocery retailing network should be configured. That study shows that distributional systems where large stores are a significant part minimise social costs when the time households spend on grocery 
shopping is given an appropriate valuation and household transport costs (including externalities) are included [4]. However, the transformation towards larger units could still be non-optimal from a welfare point of view. One potential source of market failure is a degenerative process for smaller stores caused by destructive uncoordinated individual interaction. Our hypothesis is that there is a social dilemma (see for instance Ostrom [5]), making the grocery business transformation process excessively rapid and radical. We suspect that this might increase the problem with unmatched demand for local grocery service, an obvious market failure.

In this study we find that social dilemmas exist on the grocery retailing market. Households have a positive willingness to pay (WTP) for local stores that is normally not realised since individual households lack the power to alter the supply of different grocery stores. If individual decisions were coordinated, a redistribution of market shares in favour for residential area stores would be observed.

\subsection{Purpose}

The purpose of this paper is to test if local grocery service is a utility plagued by a social dilemma, resulting in less than optimal local service. We do this by means of two stated preference questions where the existence and design of the local store is determined by one individual, who acts like a benevolent social planner, and uncoordinated action by many individuals respectively. The hypothesis is scrutinised by a comparison of the WTP for a small residential area grocery store. If a social dilemma exists, we will find a higher WTP when individual consumer behaviour determines longterm consequences for the local stores than if the outcome is a result of uncoordinated collective action.

\subsection{Outline}

The next section will introduce the reader to the concept of social dilemmas, its definition, consequences and potential solutions. Then a simple model over costs associated with shopping in stores of different size is set up. Using this model we elaborate a social dilemma hypothesis concerning local grocery service. After a description of the data set and some necessary assumptions, we estimate an utility model and compute WTP. We close the paper with discussion and conclusions.

\subsection{Social dilemmas}

A social dilemma arises when non-coordinated individual decision making leads to sub-optimal equilibria. Then each individual finds it rational to make a decision that makes everyone, including the acting individual him/herself, worse off! Social dilemmas concern products or services that can be characterised as public goods, utilities that are non-rival in consumption, i.e. one person's utilisation of the utility does not confine the other person's consumption possibilities. The dilemma is that public goods will be short in supply since individuals find it rational to free ride, i.e. use the public good without contributing to its provision. The solutions commonly suggested can be classified either as public financing or coordination. Simply excluding people who do not contribute to the public good is not efficient since the marginal cost is negligible. Thus, although it would be free, potential utility will not be realised, an obvious welfare loss.

Using a wide definition of goods, public goods and social dilemmas are found to be a widespread phenomena. The best-known instance is probably prisoner's dilemma where two suspected criminals are sentenced to a longer-term imprisonment than they would have if they had trusted each other. 
The relationship to the discussion above is clear if one thinks of 'freedom' as the public good. Another famous dilemma is the tragedy of the commons, in a seminal article by Hardin [6] exemplified by grazing cattle on a common pasture. This dilemma however arises because access to the common is administered as if it was a public good, while in fact it is not.

The pessimistic conclusions drawn from theories and experiments involving rational egoists have however been modulated by recent empirical research. It is now understood that there exists a nonnegligible share of persons whose behavioural pattern is more complex than rational egoists'. Also, the conditions for a successful cooperation are more advantageous in groups where a limited number of people interact over and over again especially if they use face-to-face communication [5].

\subsection{Convenience dimensions - public goods}

The hypothesis scrutinised in this article is that convenience dimensions provided by smaller residential area stores are public goods and consequently that the diminishing accessibility to such services is a social dilemma. To understand this it is of utmost importance to fully apprehend the separation of the convenience dimension from the groceries themselves. The social dilemma regards the convenience dimensions only, groceries are unproblematic due to their pure private good properties. Also notice that stores are designed (size, opening hours, crew, etc.) to be cost minimising for a specific volume or a specific number of 'average' consumers. Design parameters are fixed in the short run. Up to this level, an extra customer 'contributes' by reducing average costs. An extra consumer enjoying the service provided by the local store does not impede others from doing the same; on the contrary, he/she reduces the cost for doing so. Average cost for convenience dimensions is thus falling in this interval and consequently service is non-rival in consumption and a public good.

Since the service dimensions is not only non-rival in consumption but also non-excludable, they are financed by a margin on the groceries bought in the store. Therefore, consumers buying more in the store subsidises the convenience dimensions for those buying less. In fact it is people relying on others to subsidise their service that constitutes the social dilemma.

\section{MODEL}

We assume the behaviour of an household to be defined by a discrete frequency distribution over grocery volume, $f(q)$. The distribution shows how many times a month the household buys a certain amount of groceries. The household (a four-person household is assumed throughout the analysis) total amount of groceries, $Q$, and the number of shopping occasions, $F$, each month is then:

$$
\begin{aligned}
& Q=\sum_{q=0}^{\infty} f(q) q \\
& F=\sum_{q=0}^{\infty} f(q) .
\end{aligned}
$$

In a first stage the $N$ households of a certain area buy their groceries at a small $(s)$ local store close to their homes. The design of the small store, i.e. size, supply, personnel, service, etc. is optimised to meet the total local demand, $N Q$. The price setting scheme is unknown, although we know that full cost cover is possible, i.e. $p_{s} \geq A C_{s}$. Now a larger $(l)$ store is established $d_{l}$ kilometres distance from the residential area. The larger store attracts customers from a quite large area by setting a relatively low price $\left(p_{l}<p_{s}\right)$, which due to economies of scale is still a profitable level. The design of the larger 


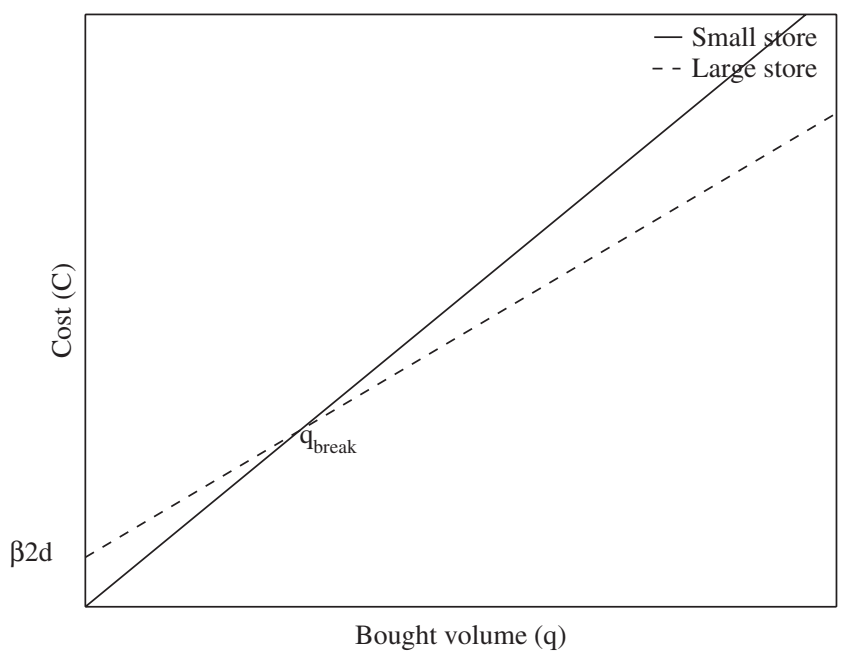

Figure 1: Break even points.

store is optimised to enable $p_{l} \geq A C_{l}$ taking competition from local area stores into account. Clearly the small store will face a reduced demand. Given prices, the market share of each store is determined by $f(q)$ and generalised transport cost of households. For consumers, there is a substantive 'fixed' cost generated by transports. The cost associated with one shopping occasion where $q$ is bought is:

$$
C_{k}=p_{k} q+\beta 2 d_{k} \quad k=s, l .
$$

where $q$ is the bought quantity of groceries, $p_{k}$ is a price index, $\beta$ is a generalised kilometre cost experienced by the consumer, $d_{k}$ is the distance between home and store and 2 indicates a round trip.

Assume for the sake of simplicity that the small store is located close enough to homes that $d_{s}$ are zero. From the point of view of a single consumer the situation is illustrated by the solid line (small store) and dashed line (large store)) in Fig. 1. The steeper line of the small store indicates a higher price, while the intercept $\beta 2 d$ represents the transport cost associated with a trip to the larger store.

Since transport costs are fixed, the cost minimising the choice of the store depends on the amount of groceries that the individual plans to buy. The small residential area store is used for small quantity convenience shopping only. The quantity above which the best choice of the consumer is shopping in the large store is denoted $q_{\text {break }}$.

For a consumer following the decision rule above, the monthly minimum cost for groceries, including distributional work performed by the consumer is captured by the following total cost (TC) function. Purchases smaller than $q_{\text {break }}$ generate costs corresponding to the first term of eqn (3), while larger volumes generate the second term.

$$
\mathrm{TC}=\sum_{q=0}^{q_{\text {break }}} f(q) C_{s}+\sum_{q_{\text {break }}}^{\infty} f(q) C_{l} .
$$

\subsection{The local store dilemma}

With competition from a large store and households using the decision rule above, the residential area store cannot maintain its present form. Should the small store go out of business, consumers 
would be imposed an extra cost equivalent to the summed cost differences where $q<q_{\text {break }}$. Using compensating variation arguments [7] we define this amount of money as a WTP to keep a small store.

$$
\mathrm{WTP}=\sum_{q=0}^{q_{\text {brakk }}} f(q)\left(C_{l}-C_{s}\right) .
$$

WTP corresponds to an unmatched demand for local service should the small store go out of business completely. But there also exists a possibility to establish a transformed small store, using a share of the WTP to make it profitable. The qualities of this 'new' store are clearly dependent on the WTP. The larger the WTP, the better local service will be provided. A market failure will take place if the WTP is too small for any type of store to exist. This demand will then be unmatched. Our hypothesis is that even if the households took into account the consequences for the local store, they would not probably change their shopping behaviour. It would be irrational since the contribution of one single customer is too small to make any difference. But, if the households' individual decisions made a difference, a behavioural difference would probably be observable. Using a stated preference approach however, we have the ability to simulate a case where the decisions of individual households were decisive for the survival of the small store. If they act different in this case than if their influence were just marginal, we claim there is a social dilemma.

We state our hypothesis in terms of WTP to keep the small store. If the threat towards the small store is a social dilemma then $\mathrm{WTP}_{\text {coordinated }}>\mathrm{WTP}_{\text {uncoordinated }}$.

\section{METHOD}

The market share of the large store is:

$$
w=\sum_{q_{\text {break }}}^{\infty} f(q) q / Q .
$$

The number of shopping occasions in the two types of stores:

$$
\begin{aligned}
& f_{s}=\sum_{0}^{q_{\text {braak }}} f(q) \\
& f_{l}=\sum_{q_{\text {break }}}^{\infty} f(q) .
\end{aligned}
$$

Using eqns (5) and (6) we can rewrite the expressions for TC and WTP :

$$
\mathrm{TC}=(1-w) Q p_{s}+w Q p_{l}+\beta 2\left[f_{l} d_{l}+f_{s} d_{s}\right]
$$

where $(1-w) Q p_{s}+w Q p_{l}$ is the total buying cost and $\beta 2\left[f_{l} d_{l}+f_{s} d_{s}\right]$ is the generalised total transport cost. Then:

$$
\mathrm{WTP}=\left(p_{l}-p_{s}\right)(1-w) q+\beta 2\left(d_{l}-d_{s}\right) f_{s} .
$$

Hence, WTP is a function of the unknown generalised kilometre cost, $\beta$. So in any setting where distances and prices are known and the way people distribute their purchases between small and large stores can be 'observed', the determination of WTP is reduced to an estimation of $\beta$. To enable computation of WTP we would like to estimate the kilometre cost $\beta$ under different circumstances. 
Since we assume that each individual strives to maximise his/her utility while shopping groceries we start with a general utility function (9).

$$
U=f(\mathrm{TC}, \mathbf{z}),
$$

where TC is the total cost function of eqn (7). Service dimensions other than distance and individual heterogeneity are collected in the vector $\mathbf{z}$.

It is then natural to define the utility function as the negative of the TC, where $\mathbf{z}$ from eqn (9) is assumed to be part of a stochastic error term. Thus we have a random utility function:

$$
U=-\left\{(1-w) Q p_{s}+w Q p_{l}+\beta 2\left[f_{l} d_{l}+f_{s} d_{s}\right]\right\}+\varepsilon
$$

\subsection{Data}

In a number of stated preference studies [2, 8, 9], individuals were asked to chose between five alternatives defined by the share of groceries bought in small residential area stores $300 \mathrm{~m}$ from home and large stores $10 \mathrm{~km}$ away, $w$. The stores also differ with respect to price, with residential area store being more expensive. The design forces respondents to optimise between the price for the relevant basket of groceries and store proximity. The surveys cover Stockholm, the capital of Sweden, and four small and middle-sized Swedish cities. The total number of observations $\left(N_{\text {tot }}\right)$ from the studies is 2149. In all questionnaires there is a question where coordinated choices determine the supply and price level in the small store. Respondents are informed that the price difference between the stores is a function of his/her individual shopping decisions. Smaller amounts bought in the residential area store generate raised prices. This could be interpreted as if the shopping behaviour of other people were identical to the behaviour of the respondent. The purpose of this question is to assess the behaviour of consumers given that the social dilemma discussed above could be mastered. This is to be compared to an additional question raised in a subset of the questionnaires $\left(N_{\text {subset }}=1303\right)$ where the relative price between the larger and the smaller store is unaffected by the individual choice. From the individual point of view the offered price and the service provided by different stores are practically independent of his or her individual choice. The purpose of this question is to mimic the uncoordinated behaviour that might generate the social dilemma. As a baseline case we set $p_{l} Q=4500$, which is based on data from the Swedish Consumer Agency [10]. Table 1 shows the implied monthly buying cost and the share of respondents that selected each alternative.

Table 1 also shows that people would buy more in the small store if they knew that other people did the same thing, i.e. if shopping behaviour were coordinated. The alternatives where $75 \%$ and $100 \%$ of the groceries are bought in the small store get a considerably larger share of answers in the coordinated case compared with the uncoordinated. Consequently fewer people chose to buy most of their groceries in the large store in the coordinated case.

\subsubsection{Shopping frequency}

The survey also includes questions about the monthly number of shopping occasions, $F$ (notice that individuals choosing different options have different average $F$ ). To determine the distance associated with each option, we have to assume how these trips are distributed between the two stores. To cover for uncertainty introduced by this assumption we use several variants. A first possibility (assumption A) is that the share of shopping occasions equals the share of groceries bought in each store, which means that the average amount (value) bought is the same in both stores. Considering Fig. 1 this is clearly unrealistic. The implication of a cost minimising strategy is larger quantities per shopping 
Table 1: Bought shares, buying cost and answer frequency.

\begin{tabular}{|c|c|c|c|c|c|}
\hline \multicolumn{2}{|c|}{ Bought share } & \multicolumn{2}{|c|}{ Uncoordinated } & \multicolumn{2}{|c|}{ Coordinated } \\
\hline Large $(w)$ & Small $(1-w)$ & Buying cost & Answers (\%) & Buying cost & Answers (\%) \\
\hline 1 & 0 & 4500 & 11.90 & 4500 & 9.77 \\
\hline 0.75 & 0.25 & 4838 & 26.25 & 4669 & 20.15 \\
\hline 0.5 & 0.5 & 5063 & 19.19 & 4838 & 13.91 \\
\hline 0.25 & 0.75 & 5175 & 19.95 & 5006 & 21.73 \\
\hline \multirow{3}{*}{0} & 1 & 5175 & 22.72 & 5175 & 34.43 \\
\hline & & & 100 & & 100 \\
\hline & & \multicolumn{2}{|c|}{$n=1303$} & \multicolumn{2}{|c|}{$n=2149$} \\
\hline
\end{tabular}

SEK is the Swedish currency. SEK/euro $=9.40, \mathrm{SEK} / \mathrm{USD}=7.11(070301)$.

Buying cost $=(1-w) Q p_{s}+w Q p_{l}$.

Table 2: Shopping frequency - three assumed distributions.

\begin{tabular}{|c|c|c|c|c|c|c|c|}
\hline \multirow[b]{2}{*}{$w$} & \multirow{2}{*}{$\begin{array}{l}\text { Stated frequency } \\
\qquad(F)\end{array}$} & \multicolumn{2}{|c|}{ A } & \multicolumn{2}{|c|}{ B } & \multicolumn{2}{|c|}{$\mathrm{C}$} \\
\hline & & $f_{l}$ & $f_{s}$ & $f_{l}$ & $f_{s}$ & $f_{l}$ & $f_{s}$ \\
\hline 1 & 17 & 17 & 0 & 17 & 0 & 17 & 0 \\
\hline 0.75 & 19 & 14.25 & 4.75 & 7.13 & 11.88 & 4.75 & 14.25 \\
\hline 0.5 & 21 & 10.5 & 10.5 & 5.25 & 15.75 & 3.5 & 17.5 \\
\hline 0.25 & 21 & 5.25 & 15.75 & 2.63 & 18.38 & 1.75 & 19.25 \\
\hline 0 & 23 & 0 & 23 & 0 & 23 & 0 & 23 \\
\hline
\end{tabular}

occasion in the large store. Still assumption A is useful as a limiting case. We then add two cases in which the average value per shopping occasion in a large store is two (B) and three (C) times larger than in the smaller store. The stated number of monthly shopping occasions per store type and the assumed distribution between large and small stores is presented in Table 2 .

\subsection{Econometric approach}

The design of our stated preference study generates a data set suitable for discrete choice analysis. Assuming the stochastic part of eqn (10), $\varepsilon$, to be independent draws from the type 1 extreme value distribution, the probabilities for the options can be expressed with a conditional logit model [11] which can be estimated from the discrete data presented in Table 1 and the shopping frequency assumptions presented in Table 2. The model can be estimated from share or frequency data [12], so all necessary information is presented in the referred tables.

$$
P\left(w_{i}\right)=\frac{\mathrm{e}^{-\left\{\left(1-w_{i}\right) Q p_{s}+w_{i} Q p_{l}+\beta 2\left[f_{l i} d_{l}+f_{s, i} d_{s}\right]\right\}}}{\sum_{j=1}^{5} \mathrm{e}^{-\left\{\left(1-w_{j}\right) Q p_{s}+w_{j} Q p_{l}+\beta 2\left[f_{l, j} d_{l}+f_{s, j} d_{s}\right]\right\}} .}
$$




\section{RESULTS}

The result of the estimations is presented in Table 3. The significance level is computed by a likelihood ratio (LR) test against the model without distance information. The test has 1 degree of freedom and can be used not only as a evaluation tool for the entire model but also as a significance test for the generalised kilometre cost, $\beta$. As is obvious from the $P$-values this estimate is highly significant under any of the frequency assumptions $\mathrm{A}-\mathrm{C}$ and both for uncoordinated and coordinated choices.

With uncoordinated decision making, the shadow kilometre cost for grocery shopping trips, $\beta$ is 2.6-4 SEK/ $\mathrm{km}$. Swedish consumer agency estimates the private kilometre cost of a new car to be 3.5 SEK (A Volvo V70 that the owner keeps for 5 years. www.konsumentverket.se), a quite astonishing correspondence showing that consumers have enough information to make individually rational decisions. Also, it shows that the approach used in the analysis produces reasonable results. If instead the consumer's decisions are coordinated, $\beta$ will be higher, approximately 4.7-5.9 SEK. In most cases $\beta$ increases, the larger share of the shopping trips that are assumed to be made in the small store. This is completely in line with expectations. One exception however is that $\beta$ is somewhat lower $(5.9 \mathrm{SEK} / \mathrm{km})$ for frequency assumption $C$ than for assumption $B(6.0 \mathrm{SEK} / \mathrm{km})$ in the coordinated case. This deviation can be explained by random variation in the estimation process.

Inserting the estimated kilometre cost, shopping frequencies and the shares bought in the large store $(w)$ in eqn (8) we get WTP for the service provided by a local grocery store (see Table 4 ). The first row of Table 4 is zero, since households that buy all groceries in the large store have no WTP for local service, but when the share bought in the large store decreases, the WTP increases. As a function of the higher kilometre cost, WTP is generally higher in the scenario where decisions are coordinated. Also, assuming a larger share of shopping trips to the smaller store also increases WTP because more trips would be made to the larger store if the small store disappeared and as a result of

Table 3: Estimations.

\begin{tabular}{lccccccc}
\hline & \multicolumn{3}{c}{ Uncoordinated } & & \multicolumn{3}{c}{ Coordinated } \\
\cline { 2 - 4 } \cline { 7 - 8 } & $\mathrm{A}$ & $\mathrm{B}$ & $\mathrm{C}$ & & $\mathrm{A}$ & $\mathrm{B}$ & $\mathrm{C}$ \\
\hline$\beta$ & 2.6 & 3.9 & 4.0 & & 4.7 & 6.0 & 5.9 \\
$\mathrm{LR}$ & 136.3 & 234.7 & 252.1 & & 739.6 & 799.2 & 739.1 \\
$P$ & 0.000 & 0.000 & 0.000 & & 0.000 & 0.000 & 0.000 \\
\hline
\end{tabular}

Table 4: WTP SEK/month/household.

\begin{tabular}{lccccccc}
\hline \multirow{2}{*}{$\begin{array}{l}\text { Share large } \\
\text { store }(w)\end{array}$} & \multicolumn{3}{c}{ Uncoordinated } & & \multicolumn{3}{c}{ Coordinated } \\
\cline { 2 - 4 } \cline { 6 - 7 } & $\mathrm{A}$ & $\mathrm{B}$ & $\mathrm{C}$ & & $\mathrm{A}$ & $\mathrm{B}$ & $\mathrm{C}$ \\
\hline 1 & 0 & 0 & 0 & & 0 & 0 & 0 \\
0.75 & 71 & 730 & 937 & & 264 & 1214 & 1462 \\
0.5 & 192 & 854 & 1021 & & 620 & 1496 & 1666 \\
0.25 & 288 & 884 & 988 & & 930 & 1633 & 1697 \\
0 & 485 & 1065 & 1110 & & 1422 & 2002 & 1958 \\
\hline
\end{tabular}


the generally higher assessment of the kilometre cost. The only exception is for $w=0$, assumption $\mathrm{C}$ in the coordinated case which is a result of the unexpected decrease in $\beta$ between assumptions $\mathrm{B}$ and C. For $w=0$, the shift from assumption B to C means nothing in terms of shopping frequency, resulting in a clear and unmasked impact from the lower $\beta$. Although WTP varies considerably, it clearly expresses a real demand for local grocery service. We summarise in the following way. In the realistic case where the decisions of individual households are uncoordinated there exists a positive WTP for the local store, beyond what is already expressed by buying from the local store in spite of its higher price. The WTP varies between different people but in this study has been shown to be roughly in the interval 0-1000 SEK per month and household. Could the decisions of households be coordinated the upper interval limit would increase with approximately $100 \%$ resulting in an interval between 0 and 2000 SEK per month and household.

\section{CONCLUSIONS}

The results clearly confirm that social dilemmas exist on the grocery retailing market. Rational households are aware of the substantial risk for service reductions when they use larger stores at some distance from home instead of using the local store in their own residential area. They have a positive WTP for local service, beyond that motivated by short-term savings, but they will not let this component inflict on the store-choice decision as long as each and every household lacks the power to alter the supply of different grocery stores on the market. If individual decisions were coordinated, a redistribution of market shares in favour for residential area stores would be observed. Under realistic circumstances though, the WTP will not be realised, which in many cases will result in a socially unwanted deterioration of local service.

The existence of an unrealised WTP clearly motivates some sort of regulatory measures. Traditionally, market intervention or institutional arrangements are used to avoid a situation with a sub-optimal short supply of public goods. Before policies are designed it is however important to consider the reasons beyond the specific social dilemma uncovered in this article. The market shares of small stores decrease as a consequence of investments in infrastructure and transportation systems that enables easy and affordable access with cars in the city. Hence, people choose in increasing amount to use larger stores, in spite of the fact that smaller stores are vanishing. To focus measures on the grocery business itself would therefore mitigate, at best, some of the problems, but the root cause would remain. Policies focused at the detailed level would in most cases be ineffective since they are outweighed by forces released by more strategic choices. A policy recommendation is to support the market for local grocery stores, not by direct regulations, but through an urban design and land use pattern that enhances markets for local service. For instance, a more diverse design of residential areas can be used to create the necessary physical prerequisites for the production of local services by making the demand more spatially concentrated. Residential areas primarily designed for pedestrians and users of public transport would for instance probably attract people who prefer local service, and thus improve conditions for smaller grocery stores.

\section{REFERENCES}

[1] Arndt, J. \& Olsen, L., A research note on economies of scale in retailing, Swedish Journal of Economics, 77(2), pp. 207-221, 1975.

[2] Svensson, T. \& Haraldsson, M., Konsekvenser av dagligvaruhandelns strukturomvandling, Rapport 485, VTI, 2002 (in Swedish).

[3] Svensson, T., Dagligvarudistributionens strukturomvandling-Drivkrafter för städers utformning och miljö, Linköping Studies in Arts and Science 179, Linköping University, 1998 (in Swedish). 
[4] Haraldsson, M. \& Svensson, T., Economic evaluation of grocery store nets in cities - a model approach. International Journal of Sustainable Development and Planning, 2(3), pp. 353-362, 2007.

[5] Ostrom, E., Collective action and the evaluation of social norms. Journal of Economic Perspectives, 14(3), pp. 137-158, 2000.

[6] Hardin, G., The tragedy of the commons. Science, 162(3859), pp. 1243-1248, 1968.

[7] Varian, H.R., Microeconomic Analysis, 3rd edn, W.W. Norton \& Company, 1992.

[8] Svensson, T., Hushållens inköpsmönster och val av dagligvarubutiker - En förstudie, Notat 6, VTI, 2001 (in Swedish).

[9] Svensson, T. \& Haraldsson, M., Hushållens inköpsmönster och val av dagligvarubutiker $i$ Trollhättan, Västerås och Östersund, Notat 62, VTI, 2001 (in Swedish).

[10] Konsumentverket, Hushållens matkostnader, Rapport 15, 1999 (in Swedish).

[11] Wooldridge, J.M., Econometric Analysis of Cross Section and Panel Data, MIT Press, 2002.

[12] Greene, W.H., Econometric Analysis, 3rd edn, Prentice Hall, 1997. 